MYCOPLASMA GENITALIUM

\title{
Mycoplasma genitalium: prevalence, clinical significance, and transmission
}

\author{
C Anagrius, B Loré, J S Jensen
}

Sex Transm Infect 2005;81:458-462. doi: 10.1136/sti.2004.012062

See end of article for authors' affiliations ....................

Correspondence to: Carin Anagrius, Department of Venereology, Falu Lasarett, SE-791 82 Falun, Sweden; carin.anagrius@ Itdalarna.se

Accepted for publication 22 February 2005
Objectives: To study the prevalence, symptoms and signs of Mycoplasma genitalium and Chlamydia trachomatis infections in STD clinic attendees and in partners of $M$ genitalium infected patients.

Methods: $M$ genitalium and $C$ trachomatis were detected by polymerase chain reaction from urethral and endocervical swab specimens in a cross sectional study among 445 female and 501 male STD clinic attendees. Partners of 26 female and 26 male $M$ genitalium positive index patients were examined.

Results: The prevalence of $C$ trachomatis and $M$ genitalium was $4 \%$ and $6.3 \%$, respectively, among the women and $5.4 \%$ and $6 \%$, respectively, among the men. Dual infections were uncommon. $M$ genitalium was strongly associated with urethritis in both men and women and with cervicitis in women. Among $M$ genitalium infected men, symptomatic urethritis was more common than asymptomatic urethritis. $M$ genitalium and $C$ trachomatis were not associated with symptoms of urethritis or cervicitis in women. Of 26 male partners of $M$ genitalium positive female index patients, 38\% were positive, and $77 \%$ of the negative partners had symptoms of urethritis. The concordance rate for 22 female partners of male index patients was $45 \%$. For both men and women the $M$ genitalium prevalence was significantly higher in partners of $M$ genitalium positive index patients than in $M$ genitalium negative index patients with urethritis and/or cervicitis.

Conclusions: $M$ genitalium is associated with urethritis in both men and women and with cervicitis in women. A high concordance rate was found among sexual partners of $M$ genitalium infected patients, indicating that the infection is sexually transmitted.
$\mathrm{T}$ he organisms Chlamydia trachomatis and Neisseria gonorrhoeae are generally accepted pathogens in urethritis and cervicitis. However, in many cases no pathogen can be identified. Possible causes are other bacterial species, nonbacterial infections such as those caused by viruses and probably non-infectious conditions. In recent years, Mycoplasma genitalium has been of increasing interest. This microbe is a very small prokaryote with the minimum of metabolism necessary for a free living cell. $M$ genitalium was first isolated in 1980 from two of 13 men with urethritis. ${ }^{12}$ Owing to the slow cell replication and fastidious growth requirements, culture is impossible to use in clinical practice. Polymerase chain reaction (PCR) ${ }^{3}{ }^{4}$ is currently the method of choice for detection.

Several studies have shown that $M$ genitalium is strongly associated with non-gonococcal urethritis (NGU), and in particular with non-chlamydial NGU (NCNGU) (recently reviewed by Taylor-Robinson and Horner ${ }^{5}$ and Jensen ${ }^{6}$ ). An independent and significant association between $M$ genitalium and mucopurulent cervicitis ${ }^{7}$ and an association to endometritis ${ }^{8}$ have also been established.

The aim of this study was to obtain information on $M$ genitalium concerning prevalence, association to clinical manifestations, and mode of transmission.

\section{METHODS}

Study population

Prevalence study

This study was performed among attendees at the STD clinic, Falun, Sweden. From September 1995 through October 1997, samples for $M$ genitalium, $C$ trachomatis, and $N$ gonorrhoeae were collected from 946 consecutive patients attending because of symptoms of sexually transmitted infections or for a check up. A total of 445 women and 501 men were included. The median age of the women was 25 years (range
14-55). The median age of the men was 26 years (range 17$67)$.

Partner notification study

In order to obtain information about the transmission of $M$ genitalium, sexual partners of $M$ genitalium infected patients were traced whenever possible in the same way as partner notification for $C$ trachomatis is performed in Sweden. ${ }^{9-11}$ According to this legislation, sexual partners within at least 6 months should be traced and examined as follows.

(1) Patient referral: partners are informed by patient.

(2) Provider referral: patient reports name and address or at least telephone number of partner to the contact tracer, a health worker.

(3) Conditional approach: initial patient or provider referral is followed by a stronger provider referral after an agreed interval. If a named partner refuses to be examined the medical officer of health is informed.

However, since $M$ genitalium is not included in the legislation, we tried to motivate index patients to ask their partners to be examined. As a minimum, partners in "ongoing relationships" were examined. No provider referral was practised and no letters were sent to partners. $M$ genitalium positive patients identified from November 1997 through December 2001 were included as index patients. During this period, only selected patients were examined for $M$ genitalium. Contact tracing during the prevalence study was not practicable because of a delay between examination and

Abbreviations: FVU, first void urine; hpf, high power field; NCNGU, non-chlamydial non-gonococcal urethritis; NGU, non-gonococcal urethritis; PCR, polymerase chain reaction; PMNLs, polymorphonuclear leucocytes 
the availability of the test result. For comparison, partners of index patients treated for urethritis or cervicitis without known infection with $C$ trachomatis, Mycoplasma genitalium, or $N$ gonorrhoeae (non-specific infection) were examined. This was performed during 2003 as data concerning partner notification in non-specific infection were not available earlier.

\section{Clinical assessment}

Patients were regarded as having symptoms of urethritis if they complained of dysuria or urgency and for males if they had noticed a discharge. In females, discharge was regarded as a symptom of cervicitis.

Microscopic urethritis was diagnosed if $>4$ polymorphonuclear leucocytes (PMNLs) per high power field (hpf) (1000 $\times$ magnification) were observed in $>4$ fields in a methylene blue stained smear of urethral secretion collected with a plastic loop from both men and women.

Microscopic cervicitis was diagnosed if $\geqslant 30$ PMNLs per hpf were observed in $>4$ fields in a methylene blue stained smear of cervical secretion collected with a cotton tipped swab.

\section{Clinical specimens for microbiological analysis}

During the prevalence study, male urethral specimens were taken with a cotton tipped swab transported in a tube with $2 \mathrm{ml}$ 2-SP medium From women, endocervical and urethral swabs were transported in a tube with 2-SP medium

During the partner notification study, specimens from men consisted of first void urines (FVU) and from females endocervical swabs were placed in the tube containing the woman's FVU specimen.

The specimens were refrigerated and transported to the laboratory within 1-18 hours. Specimens in 2-SP were frozen before testing, whereas urines were not.

\section{Microbiological methods}

PCR for $C$ trachomatis was performed by the Roche Cobas Amplicor system (Roche Diagnostics Scandinavia AB, Bromma Sweden) following the guidelines from the manufacturer. PCR tests for $C$ trachomatis and $M$ genitalium were performed on the same specimen.

Sample preparation for the $M$ genitalium PCR was performed by centrifuging $250 \mu \mathrm{l}$ of the specimen in 2-SP medium at $30000 \times g$ for 15 minutes, resuspending the pellet in $50 \mu \mathrm{l}$ lysis buffer (Roche $C$ trachomatis sample preparation kit) with $200 \mu \mathrm{g}$ proteinase $\mathrm{K} / \mathrm{ml}$, incubating at $55^{\circ} \mathrm{C}$ for 30 minutes, and at $94^{\circ} \mathrm{C}$ for 10 minutes. After heat treatment, $50 \mu \mathrm{l}$ specimen diluent (Roche $C$ trachomatis sample preparation kit) was added. Specimens were left for 30 minutes at room temperature before the PCR was performed. DNA extraction of urine was performed using the automated MagNA Pure LC (Roche Diagnostics) with DNA Isolation Kit I protocol. Before processing in the MagNA Pure, $2 \mathrm{ml}$ of urine was centrifuged for 15 minutes at $30000 \times \mathrm{g}$. Most of the supernatant was discarded, leaving a final volume of $300 \mu \mathrm{l}$. Of this suspension $200 \mu \mathrm{l}$ was processed and DNA was eluted in a volume of $100 \mu \mathrm{l}$. All samples were tested in a
PCR using primers for the 16SrRNA gene. ${ }^{12}$ Positive results in the first PCR were confirmed in a new PCR using MgPal and $\mathrm{MgPa} 3$ primers. ${ }^{3}$ PCR products were visualised after gel electrophoresis in ethidiumbromide stained gels.

$N$ gonorrhoeae was detected by culture.

\section{Statistical analysis}

Fisher's exact test was used for statistic analysis of categorical variables. The Mann-Whitney test was used to test for differences in continuous variables.

\section{RESULTS}

\section{Prevalence study}

Demographics

Among the 946 examined patients, $M$ genitalium was detected in $58(6.1 \%) ; 30(6.0 \%)$ of the 501 men, and $28(6.3 \%)$ of the 445 women. $C$ trachomatis was detected in 45 patients (4.6\%); $27(5.4 \%)$ men and 18 (4\%) women. Two men and one woman were co-infected with $M$ genitalium and $C$ trachomatis. One man and two women were infected with $N$ gonorrhoeae. They were excluded from the study group, which thus consisted of patients with and without non-gonococcal urethritis and cervicitis.

The median age of the $M$ genitalium infected men was 26 years (range 17-40 years). This was not different from the $C$ trachomatis positive (median 24, range 18-43) or from the $C$ trachomatis and $M$ genitalium negative group (median 26, range 17-67). The $C$ trachomatis positive men, however, were younger than the $C$ trachomatis and $M$ genitalium negative men $(\mathrm{p}=0.03)$ (Mann-Whitney test). The median age of the $M$ genitalium infected women was 25 years (range 19-54 years). This was not different from the $C$ trachomatis positive (median 22, range 18-30) or $C$ trachomatis and $M$ genitalium negative groups (median 25, range 14-55) (Mann-Whitney test).

\section{Associations between $M$ genitalium, C trachomatis, and symptoms and microscopic signs of urethritis in males}

$M$ genitalium was detected in 17 (13.6\%) of 125 men with symptomatic urethritis, and in two (1.2\%) of 161 men without symptoms or microscopic signs of urethritis $(\mathrm{p}<0.0001)$ (table 1). The presence of $M$ genitalium was significantly associated both with symptoms and with microscopic signs. This association was also seen for $C$ trachomatis. If patients co-infected with $M$ genitalium and $C$ trachomatis were excluded, 17 (61\%) of the $28 \mathrm{M}$ genitalium positive men had symptoms compared to $15(60 \%)$ of the 25 men with C trachomatis infection (NS). Likewise, 26 (93\%) of the $M$ genitalium positive men had urethritis as defined by microscopy compared to $24(96 \%)$ of the C trachomatis infected men (table 1) (NS). All $M$ genitalium infected men with symptoms also had microscopic signs. Arthritis was reported by three of the men infected with $M$ genitalium but not by any of those with $C$ trachomatis. Two of the men with arthritis were referred with the question of sexually acquired arthritis.

Table 1 Symptoms (S) and microscopic signs (M) in men infected with Mycoplasma genitalium (Mg) and Chlamydia trachomatis $(\mathrm{Ct})$, respectively

\begin{tabular}{|c|c|c|c|c|c|c|c|}
\hline & $\begin{array}{l}M-S- \\
(n=161)\end{array}$ & $\begin{array}{l}M+S_{+} \\
(n=125)\end{array}$ & $p$ Value & $\begin{array}{l}M+S- \\
(n=151)\end{array}$ & p Value & $\begin{array}{l}M-S_{+} \\
(n=61)\end{array}$ & p Value \\
\hline $\begin{array}{l}\mathrm{Mg}+\mathrm{Ct}-(\mathrm{n}=28) \\
\mathrm{Mg}-\mathrm{Ct}+(\mathrm{n}=25)\end{array}$ & $\begin{array}{l}2(1.2 \%) \\
0\end{array}$ & $\begin{array}{l}17(13.6 \%) \\
15(12.0 \%)\end{array}$ & $\begin{array}{l}<0.0001 \\
<0.0001\end{array}$ & $\begin{array}{l}9(6 \%) \\
9(6 \%)\end{array}$ & $\begin{array}{l}0.03 \\
0.001\end{array}$ & $\begin{array}{l}0(0 \%) \\
1(0.2 \%)\end{array}$ & $\begin{array}{l}\text { NS (0.99) } \\
\text { NS }(0.27)\end{array}$ \\
\hline
\end{tabular}

Total number of men in the study was 500. Two men co-infected with $M$ genitalium and $C$ trachomatis were excluded from the comparison. $p$ Values given for comparison with the $\mathrm{M}-\mathrm{S}-$ group. 
Table 2 Symptoms (S) and microscopic signs (M) in women infected with Mycoplasma genitalium (Mg) and Chlamydia trachomatis (Ct), respectively

\begin{tabular}{|c|c|c|c|c|c|c|c|}
\hline & $\begin{array}{l}M-S- \\
(n=138)\end{array}$ & $\begin{array}{l}M+S_{+} \\
(n=129)\end{array}$ & p Value & $\begin{array}{l}M+S- \\
(n=85)\end{array}$ & p Value & $M-S+(n=90)$ & p Value \\
\hline $\mathrm{Mg}+\mathrm{Ct}-(\mathrm{n}=27)$ & $3(2.2 \%)$ & $15(11.6 \%)$ & 0.003 & $6(7.0 \%)$ & NS (0.09) & $3(3.3 \%)$ & NS (0.68) \\
\hline $\mathrm{Mg}-\mathrm{Ct}+(\mathrm{n}=17)$ & $6(4.3 \%)$ & $5(3.9 \%)$ & NS (0.99) & $5(5.9 \%)$ & NS $(0.75)$ & $1(1.1 \%)$ & NS $(0.25)$ \\
\hline
\end{tabular}

Total number of women in the study was 443 . One woman co-infected with M genitalium and $C$ trachomatis was excluded from the comparison. $\mathrm{p}$ Values given for comparison with the $\mathrm{M}-\mathrm{S}-$ group.

\section{Associations between M genitalium, C trachomatis, and symptoms and microscopic signs of urethritis and cervicitis in females}

Of the 443 examined women, 130 had symptoms as well as microscopic signs of urethritis and/or cervicitis. $M$ genitalium was detected in $16(12.3 \%)$ of those with and in three $(2.2 \%)$ of the 138 women without urethritis or cervicitis $(\mathrm{p}=0.001)$. One of the women with microscopic signs was co-infected with $M$ genitalium and $C$ trachomatis (table 2). Symptoms regardless of microscopic signs were not associated with $M$ genitalium infection, whereas microscopic signs of urethritis and/or cervicitis were strongly associated with $M$ genitalium infection (table 2). For the $C$ trachomatis infected women, no association could be shown between symptoms and microscopic signs (table 2). Symptoms of urethritis or cervicitis were reported by $18(67 \%)$ of the $27 \mathrm{M}$ genitalium positive women compared to six (35\%) of the 17 C trachomatis infected women (NS) (table 2).

Microscopic signs of cervicitis without concomitant urethritis were seen in 30 of the women. Of these, $M$ genitalium was detected in four (13.3\%) compared to six $(2.6 \%)$ of the 227 women without microscopic signs $(p=0.02)$ (table $3 \mathrm{~A})$. Microscopic signs of urethritis without concomitant cervicitis were seen in 129 women. Of these, $M$ genitalium was detected in $11(8.5 \%)$ compared to six $(2.6 \%)$ of women without microscopic signs $(p=0.02)$. $M$ genitalium was significantly associated with cervicitis regardless of concomitant urethritis $(p=0.006) \quad($ table $3 \mathrm{~A})$ and with urethritis regardless of concomitant cervicitis $(\mathrm{p}=0.005)$ (table $3 \mathrm{~B})$. C trachomatis was not associated with urethritis or cervicitis (table 3 ).

If dysuria and/or urgency were considered symptoms of urethritis and discharge was considered a symptom of cervicitis, no correlation between the presence of microscopic urethritis or cervicitis and their corresponding symptoms could be found. This held true for both $M$ genitalium positive, $C$ trachomatis positive and $M$ genitalium and $C$ trachomatis negative patients. Although the number of patients studied was small, not even a trend was observed towards the expected correlation (table 4).

\section{Partner notification study}

Partner notification was performed for 52 index patients, 26 women and 26 men, infected with $M$ genitalium.

The $26 M$ genitalium infected women reported 38 male partners. Twenty six (68\%) of the male partners were examined for $M$ genitalium and 10 (38\%) were positive.

Examination was performed on 22 (73\%) of 30 female partners reported by 26 male index patients. Ten (45\%) were infected.

Symptoms and microscopic signs in partners with negative PCR for $M$ genitalium are presented in table 5. Surprisingly, six (50\%) of the $13 \mathrm{M}$ genitalium negative partners of $M$ genitalium positive women, where this information was available, had microscopic urethritis and $10(77 \%)$ had symptoms. Thus, it could be considered likely that at least some of these men were indeed infected with $M$ genitalium but remained undetected for unknown reasons. Likewise, nine $(82 \%)$ of the $11 M$ genitalium negative female partners of $M$ genitalium positive men had symptoms and/or microscopic signs of cervicitis/urethritis. In the comparison group 61 female and 80 male partners of index patients with NSU were examined. $M$ genitalium was found in one (1.6\%) of the females and in four $(5 \%)$ of the males. C trachomatis was found in one $(1.6 \%)$ of the females. Thus, $M$ genitalium was found significantly more often in partners of $M$ genitalium positive patients than in partners of patients with non-symptomatic urethritis $(\mathrm{p}<0.0001$ for both male and female partners $)$

\section{DISCUSSION}

This is one of the very few true prevalence studies concerning $M$ genitalium, in contrast with the many case-control studies published thus far. In this study, $M$ genitalium was found more often than $C$ trachomatis in both men and women. Furthermore, the prevalence of $C$ trachomatis in male patients with NGU was only $9 \%$. The reason for the low prevalence of $C$ trachomatis is not clear. $C$ trachomatis infection is notifiable and is included in the Swedish legislation on STIs; therefore, partner tracing can be performed more rigorously than in many other countries. In recent years, however, this has not

Table 3 Microsopic cervicitis (>30 PMNL/hpf) (A) and microsopic urethritis (>4 PMNL/hpf) (B) in 443 women according to Mycoplasma genitalium $(\mathrm{Mg})$ and Chlamydia trachomatis $(\mathrm{Ct})$ infection status. One woman co-infected with $\mathrm{M}$ genitalium and C trachomatis was excluded from the comparison.

\begin{tabular}{|c|c|c|c|c|c|c|c|}
\hline & $\begin{array}{l}\text { No cervicitis } \\
\text { no urethritis } \\
(n=227)\end{array}$ & $\begin{array}{l}\text { Cervicitis } \\
\text { no urethritis } \\
(n=30)\end{array}$ & p Value & $\begin{array}{l}\text { All cervicitis } \\
(n=84)\end{array}$ & p Value & $\begin{array}{l}\text { Cervicitis } \\
\text { and urethritis } \\
(\mathrm{n}=54)\end{array}$ & p Value \\
\hline \multicolumn{8}{|c|}{ (A) Microsopic cervicitis (>30 PMNL/hpf) } \\
\hline $\mathrm{Mg}+\mathrm{Ct}-(\mathrm{n}=27)$ & $6(2.6 \%)$ & $4(13.3 \%)$ & 0.02 & $9(10.6 \%)$ & 0.006 & $5(9.1 \%)$ & 0.04 \\
\hline $\begin{array}{l}\mathrm{Mg}-\mathrm{Ct}+(\mathrm{n}=17) \\
\text { (B) Microsopic urethritis (>4 }\end{array}$ & $\begin{array}{l}7(3.1 \%) \\
\text { PMNL/hpf) }\end{array}$ & $1(3.3 \%)$ & NS (0.99) & $5(5.9 \%)$ & NS (0.31) & $4(7.3 \%)$ & NS (0.23) \\
\hline $\mathrm{Mg}+\mathrm{Ct}-(\mathrm{n}=27)$ & $6(2.6 \%)$ & $11(8.5 \%)$ & 0.02 & $17(9.2 \%)$ & 0.005 & $5(9.1 \%)$ & 0.04 \\
\hline $\mathrm{Mg}-\mathrm{Ct}+(\mathrm{n}=17)$ & $7(3.1 \%)$ & $5(3.9 \%)$ & NS $(0.76)$ & $9(4.9 \%)$ & NS (0.44) & $4(7.3 \%)$ & NS (0.23) \\
\hline
\end{tabular}


Table 4 Distribution of symptoms in 443 women according to Mycoplasma genitalium $(\mathrm{Mg})$ and Chlamydia trachomatis $(\mathrm{Ct})$ infection status and their relation to microscopic cervicitis (>30 PMNL/hpf) and/or urethritis (>4 PMNL/hpf). One woman co-infected with $M$ genitalium and $C$ trachomatis was excluded from the comparison

\begin{tabular}{|c|c|c|c|c|}
\hline & Discharge & Dysuria & Urgency & Any symptom \\
\hline \multicolumn{5}{|l|}{$\mathrm{Mg}+\mathrm{Ct}-(\mathrm{n}=27)^{*}$} \\
\hline Cervicitis $(n=4)$ & 0 & $2(50 \%)$ & 0 & $2(50 \%)$ \\
\hline Urethritis $(n=11)$ & $6(55 \%)$ & $1(9 \%)$ & $1(9 \%)$ & $8(73 \%)$ \\
\hline Both $(n=5)$ & $3(60 \%)$ & $2(40 \%)$ & $1(20 \%)$ & $4(80 \%)$ \\
\hline None $(n=6)$ & $1(17 \%)$ & 2 (33\%) & 0 & $3(50 \%)$ \\
\hline \multicolumn{5}{|l|}{$\mathrm{Mg}-\mathrm{Ct}+(\mathrm{n}=17)$} \\
\hline Cervicitis $(n=1)$ & 0 & 0 & 0 & 0 \\
\hline Urethritis $(n=5)$ & $1(20 \%)$ & 0 & $1(20 \%)$ & $2(40 \%)$ \\
\hline Both $(n=4)$ & $2(50 \%)$ & $1(25 \%)$ & $1(25 \%)$ & $3(75 \%)$ \\
\hline None $(n=7)$ & $1(14 \%)$ & 0 & 0 & $1(14 \%)$ \\
\hline \multicolumn{5}{|l|}{$\mathrm{Mg}-\mathrm{Ct}-(\mathrm{n}=398)^{*}$} \\
\hline Cervicitis $(n=25)$ & $8(32 \%)$ & $8(32 \%)$ & $1(4 \%)$ & $16(64 \%)$ \\
\hline Urethritis $(n=113)$ & 42 (37\%) & $20(18 \%)$ & $12(11 \%)$ & $67(59 \%)$ \\
\hline Both $(n=45)$ & $18(40 \%)$ & $9(20 \%)$ & 0 & $26(57 \%)$ \\
\hline None $(n=214)$ & $47(22 \%)$ & 25 (12\%) & $24(11 \%)$ & $86(40 \%)$ \\
\hline
\end{tabular}

been sufficient to ensure a decreasing prevalence of $C$ trachomatis infection in Sweden in general. The age distribution of patients infected with the two pathogens was not significantly different, indicating that they may share a common behavioural and biological profile. The strong association between $M$ genitalium and male urethritis independently of $C$ trachomatis found in this study strongly indicates that it has an aetiological role in urethritis. Our findings confirm results from several other studies regarding the association between $M$ genitalium and NGU in general and NCNGU in particular (see Jensen ${ }^{6}$ for review). We found that almost all $M$ genitalium and $C$ trachomatis positive male patients had urethritis (93\% and 96\%, respectively), whereas only less than two thirds had symptoms $(61 \%$ and $64 \%$, respectively). For both pathogens, the high proportion of asymptomatic carriers among the infected would facilitate the spread of the infection. Even though many $M$ genitalium patients are asymptomatic, more patients had symptomatic than asymptomatic urethritis in this study. This is in accordance with earlier studies on smaller numbers of patients. ${ }^{13} 14$

The remarkably few patients with gonorrhoea reflected the low prevalence of this infection in Sweden. Only 210 cases were reported in 1996 in a population of 8.5 million.

Table 5 Symptoms and signs among $12 \mathrm{Mg}$ - and 10 $\mathrm{Mg}+$ female partners of 26 male index patients and in 16 $\mathrm{Mg}$ - and $10 \mathrm{Mg}$ + male partners of 26 female index patients.

\begin{tabular}{lcllll}
\hline & $\mathbf{M}+\mathbf{S}_{+}$ & $\mathbf{M}+\mathbf{S}_{-}$ & $\mathbf{M}-\mathbf{S}_{+}$ & $\mathbf{M}-\mathbf{S}-$ & Unknown \\
\hline $\begin{array}{l}\text { Female } M g- \\
(n=12)\end{array}$ & $6^{*}$ & 2 & 1 & 2 & 1 \\
$\begin{array}{l}\text { Female } M g+ \\
(n=10)\end{array}$ & 4 & 5 & 1 & 0 & \\
$\begin{array}{l}\text { Male Mg- } \\
(n=16)\end{array}$ & $6+$ & 0 & 4 & 3 & 3 \\
$\begin{array}{l}\text { Male Mg+ } \\
(n=10)\end{array}$ & 3 & 5 & 0 & 1 & 1 \\
\hline
\end{tabular}

*Two also had a history of irregular bleeding.

†One male partner was co-infected with Chlamydia trachomatis, and one male partner had arthritis.

$M$, microscopic urethritis and or cervicitis; S, subjective symptoms of urethritis and or cervicitis. One woman and four men did not have microscopic examination performed.
The few studies performed in women have indicated that $M$ genitalium might be a pathogen in cervicitis. ${ }^{75}{ }^{16}$ This is in agreement with our findings. We detected $M$ genitalium five times more often in women with cervicitis than in those without ( $13.3 \%$ compared to $2.6 \%$ ). Casin et al, ${ }^{17}$ however, did not show such an association. As a definition of cervicitis $\geqslant 10 \mathrm{PMNs} / \mathrm{hpf}$ was used compared with $\geqslant 30$ in the present study. They also found a remarkably high prevalence of $M$ genitalium $(38 \%)$ in comparison with the prevalence of $C$ trachomatis $(8 \%)$ raising concern about the specificity of the PCR method used.

In the present study, $M$ genitalium was detected three times more often in women with urethritis than in those without, (9.2\% compared to $2.6 \%$ ). This is to our knowledge the first study to show an association between $M$ genitalium infection and female urethritis.

Discharge as reported by the women may be caused by urethritis as well as by cervicitis. Discharge from the urethra is probably a less important symptom in females than in males. Without microscopy, discharge from the vagina caused by bacterial vaginosis or candidiasis cannot be differentiated from discharge caused by cervicitis, and more than one condition may be present at the same time. Bacterial vaginosis may be a marker of STI as it is found more often in women with $C$ trachomatis infection. ${ }^{16}$

The results of a few studies, apart from the present one, have indicated that $M$ genitalium is a STI. Keane et al ${ }^{18}$ studied female partners of men with and without NGU and found $M$ genitalium only in partners of men with NGU. Seven (58\%) of the 12 partners of $M$ genitalium positive male index were positive, and similarly, Falk et a ${ }^{19}$ found $67 \%$ positive female partners. These figures are slightly higher than the $45 \%$ positive female partners of $M$ genitalium positive men found in this study, but not statistically significantly different. The surprising finding that $50 \%$ of $13 \mathrm{M}$ genitalium negative male partners of $M$ genitalium positive women had microscopic urethritis and that $77 \%$ had symptoms raises concern that the diagnostic methods may need improvement. The recent finding that $20 \%$ of urogenital swab specimens contain $<1$ genome copy/ $\mu$ l of the pretreated specimen indicates that sample preparation methods may need to be improved..$^{20}$ Furthermore, it would be interesting to examine first void morning urine specimens from such discrepant couples since this specimen type may provide a higher sensitivity. ${ }^{21}$

A study based on serological data ${ }^{22}$ found a significantly higher prevalence of antibodies against $M$ genitalium in STD 


\section{Key messages}

- Mycoplasma genitalium is strongly associated with microscopic urethritis in both men and women and with microscopic cervicitis in women

- Symptomatic urethritis is more common than asymptomatic urethritis in $M$ genitalium positive men

- In women, symptoms of urethritis and cervicitis do not correlate with microscopic urethritis and cervicitis

- Partners of $M$ genitalium infected men and women were significantly more often infected with $M$ genitalium than partners of patients with non-specific infection. This supports the notion that $M$ genitalium is sexually transmitted

clinic attendees than in healthy blood donors, indirectly supporting the notion that it is spread via sexual transmission.

In our prevalence study, three men infected with $M$ genitalium had arthritis. In the partner notification study, one man infected with $M$ genitalium and one male partner with negative PCR for $M$ genitalium, but with symptoms and microscopic signs of urethritis also had arthritis. A possible causal association between $M$ genitalium infection and arthritis has been implicated earlier by the detection of $M$ genitalium from the knee joint of a patient with Reiter's syndrome ${ }^{23}$ but this relation needs to be investigated further.

In conclusion, this study has further substantiated the role of $M$ genitalium in lower genital tract infections and documented that $M$ genitalium is sexually transmitted with a transmission rate comparable to that of $C$ trachomatis. Further work is still needed, particularly in establishing the optimal treatment and in documenting upper genital tract disease.

\section{CONTRIBUTORS}

CA initiated the study, examined all patients, collected the data, and wrote the first draft of the manuscript; BL was responsible for the $N$ gonorrhoeae, $M$ genitalium, and $C$ trachomatis tests, she provided major contributions to the design of the study, analysis of the data, and writing of the manuscript; JSJ provided advice on the $M$ genitalium tests and the design of the study, he provided major contributions in the data analysis and in writing the manuscript.

\section{Authors' affiliations}

C Anagrius, Department of Venereology, Falu Lasarett, SE-791 82 Falun, Sweden

B Loré, Department of Clinical Microbiology, Falu Lasarett, SE-791 82 Falun, Sweden

J S Jensen, Statens Serum Institut, Mycoplasma Laboratory, DK-2300 Copenhagen S, Denmark

Sources of financial support: This work was supported by grants from Centre for Clinical Research Dalarna, Sweden.

Conflict of interest: no author had any conflict of interest, either financial or personal, that may have biased his or her actions.

Meetings at which part of these data were presented: The Swedish Microbiology Spring meeting, Örebro, Sweden, May 2002 and Kalmar,
Sweden, April 2004; ISSTDR, Ottawa, Canada, July 2003; Nordic Congress of Dermatology and Venereology, Odense, Denmark, May 2004.

This study was approved by the ethics committee, Dalarna, Sweden, and all participants provided informed consent.

Parts of these data have previously been published in Swedish (Anagrius C, Lore B. Läkartidningen 2002;99:4854-5, 4858-9).

\section{REFERENCES}

1 Tully JG, Taylor-Robinson D, Cole RM, et al. A newly discovered mycoplasma in the human urogenital tract. Lancet 1981;1:1288-91.

2 Tully JG, Taylor-Robinson D, Rose DL, et al. Mycoplasma genitalium, a new species from the human urogenital tract. Int I Syst Bacteriol 1983;33:387-96

3 Jensen JS, Uldum SA, Søndergård-Andersen J, et al. Polymerase chain reaction for detection of Mycoplasma genitalium in clinical samples. J Clin Microbiol 1991;29:46-50.

4 Palmer HM, Gilroy CB, Furr PM, et al. Development and evaluation of the polymerase chain reaction to detect Mycoplasma genitalium. FEMS Microbiol Lett 1991;61:199-203.

5 Taylor-Robinson D, Horner PJ. The role of Mycoplasma genitalium in nongonococcal urethritis. Sex Transm Infect 2001;77:229-31.

6 Jensen JS. Mycoplasma genitalium: the aetiological agent of urethritis and other sexually transmitted diseases. J Eur Acad Dermatol Venereol 2004; 18:1-11.

7 Manhart LE, Critchlow CW, Holmes KK, et al. Mucopurulent cervicitis and Mycoplasma genitalium. J Infect Dis 2003;187:650-7.

8 Cohen CR, Manhart LE, Bukusi EA, et al. Association between Mycoplasma genitalium and acute endometritis. Lancet 2002;359:765-6.

9 The Communicable Diseases Act (Smittskyddslag 1988:1472). Stockholm, 1988.

10 Ramstedt K. An epidemiological approach to sexually transmitted diseases with special reference to contact tracing and screening. Acta Derm Venereol Stockh 1991;157(suppl): 1-45

11 Eitrem R, Erenius M, Meeuwisse A. Contact tracing for genital Chlamydia trachomatis in a Swedish county. Sex Transm Dis 1998;25:433-6.

12 Jensen JS, Borre MB, Dohn B. Detection of Mycoplasma genitalium by PCR amplification of the 16S rRNA gene. J Clin Microbiol 2003;41:261-6.

13 Björnelius E, Lidbrink P, Jensen JS. Mycoplasma genitalium in non-gonococcal urethritis - a study in Swedish male STD patients. Int J STD AIDS 2000;11:292-6.

14 Horner PJ, Taylor Robinson D. Mycoplasma genitalium and non-gonococcal urethritis. Lancet 1994;343:790-1.

15 Uno M, Deguchi T, Komeda H, et al. Mycoplasma genitalium in the cervices of Japanese women. Sex Transm Dis 1997;24:284-6.

16 Falk L, Fredlund H, Jensen JS. Signs and symptoms of urethritis and cervicitis among women with or without Mycoplasma genitalium or Chlamydia trachomatis infection. Sex Transm Infect, (in press).

17 Casin I, Vexiau-Robert D, De La SP, Eche A, et al. High prevalence of Mycoplasma genitalium in the lower genitourinary tract of women attending a sexually transmitted disease clinic in Paris, France. Sex Transm Dis 2002;29:353-9.

18 Keane FE, Thomas BJ, Gilroy CB, et al. The association of Chlamydia trachomatis and Mycoplasma genitalium with non-gonococcal urethritis: observations on heterosexual men and their female partners. Int J STD AIDS 2000;11:435-9.

19 Falk L, Fredlund H, Jensen JS. Symptomatic urethritis is more prevalent in men infected with Mycoplasma genitalium than with Chlamydia trachomatis. Sex Transm Infect 2004;80:289-93.

20 Jensen JS, Biörnelius E, Dohn B et al. Use of TaqMan 5' nuclease real-time PCR for quantitative detection of Mycoplasma genitalium DNA in males with and without urethritis who were attendees at a sexually transmitted disease clinic. J Clin Microbiol 2004;42:683-92.

21 Jensen JS, Biörnelius E, Dohn B, et al. Comparison of first void urine and urogenital swab specimens for detection of Mycoplasma genitalium and Chlamydia trachomatis by PCR in patients attending a sexually transmitted disease clinic. Sex Transm Dis. 2005: (in press).

22 Wang RY, Grandinetti T, Shih JW, et al. Mycoplasma genitalium infection and host antibody immune response in patients infected by HIV, patients attending STD clinics and in healthy blood donors. FEMS Immunol Med Microbiol 1997; 19:237-45

23 Taylor-Robinson D, Gilroy CB, Horowitz S, et al. Mycoplasma genitalium in the joints of two patients with arthritis. Eur J Clin Microbiol Infect Dis 1994;13:1066-9. 